\title{
Post COVID-19 Subacute Thyroiditis: A Case Report
}

\author{
Mohammed A. Abusaiba', Najah R. Hadi ${ }^{1 *}$, Jan Fedacko², Ram B Singh ${ }^{3}$, Hayder A. Al-Aubaidy
}

\author{
Faculty of Medicine, University of Kufa, Al-Najaf, Iraq. \\ ${ }^{2}$ Faculty of Medicine, Safrik University, Slovakia. \\ ${ }^{3}$ Halberg Hospital and Research Institute, Moradabad, India. \\ ${ }^{4}$ School of Life Sciences, La Trobe University, VIC, 3086, Australia. \\ *Correspondence to: Professor Najah R. Hadi (E-mail: drnajahhadi@yahoo.com) \\ (Submitted: 17 August 2021 - Revised version received: 29 August 2021 - Accepted: 14 September 2021 - Published online: 26 October 2021)
}

\begin{abstract}
Subacute thyroiditis is a non-suppurative inflammation of the thyroid gland, which usually develops after viral infection to the upper respiratory tract, accompanied by pain in the neck radiated to the jaw and fever. This is a case report study for a 43 -year-old woman, who developed subacute thyroiditis 6 weeks following coronavirus disease (COVID-19)
\end{abstract}

\section{Background}

Subacute thyroiditis (SAT) is usually associated by local swelling and inflammation of the thyroid gland secondary to viral infections. SAT usually occurs $2-8$ weeks after the occurrence of viral upper respiratory tract infection. ${ }^{1}$ The pain in SAT is usually a sudden, may start in one lobe but rapidly spread to include all the gland. It is associated with swelling of the thyroid gland, and tenderness over the anterior side of the neck. It is also frequently associated with constitutional symptoms, such as fever, myalgia, arthralgia, generalized weakness, and sore throat. ${ }^{2}$

\section{Case Report}

A 43-year-old female patient with no previous history of chronic disease were presented to the outpatient clinic at Al-Sader Teaching Hospital, Al-Najaf, Iraq. The patient was complaining of sore throat and fever with sudden onset of pain started in the neck, then it is radiating to the lower jaw. She has recently been diagnosed by SARS-CoV-2 (COVID-19), 6 weeks ago, confirmed by a nasopharyngeal swab test following cough fever and shortness of breath.

The patient had no family history of chronic illnesses nor previous infection with COVID-19. She had no contact with known positive case. She also did not have a recent travel history. On examination, her neck was red, swollen, and tender by palpation. Tonsils were hyperemic. She had fever (her body temperature was $38.3^{\circ} \mathrm{C}$ ) and tachycardia (her heart rate was 130 beats per a minute). No other abnormalities were found on examinations.

Thyroid ultrasound examination revealed a heterogenous parenchyma with patchy infiltrations and hypoechoic areas observed in both thyroid lobes (Figure 1).

Her biochemical laboratory examination results are as follows:

Thyroid-stimulating hormone (TSH)/thyrotropin ratio was 0.95 ; thyroxine (T4) level was $95.7 \mu \mathrm{IU} / \mathrm{mL}$; triiodothyronine (T3) level was $1.5 \mu \mathrm{mol} / \mathrm{mL}$, Table 1 . Her blood examination for complete blood count shows generalized leukocytosis, erythrocyte sedimentation rate (ESR) was $65 \mathrm{~mm} / \mathrm{h}$; and Creactive protein (CRP) level was $35 \mathrm{mg} / \mathrm{dL}$, Table 1.

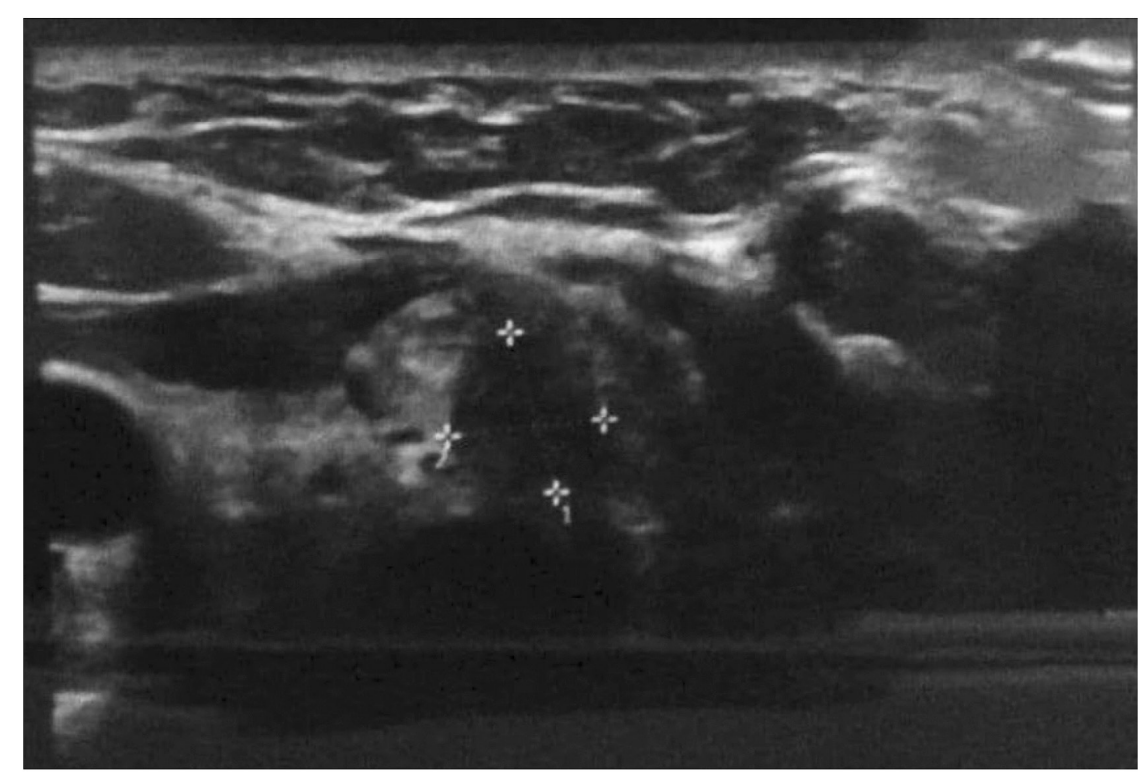

Fig. 1 Ultrasound imaging of the thyroid for the SAT patient, showing heterogenous tissue with localised inflammatory areas. 


\begin{tabular}{lc}
\hline $\begin{array}{l}\text { Table 1. Biochemical analysis for the patients with subacute } \\
\text { thyroiditis following COVID-19 infection }\end{array}$ \\
\hline \multicolumn{2}{l}{ Parameters } \\
\hline Thyroid Function Test \\
Thyroid Stimulating Hormone/thyrotropin ratio & $0.95 \mathrm{ulU} / \mathrm{ml}$ \\
Thyroxine (T4) & $1.5 \mathrm{umol} / \mathrm{ml}$ \\
Triiodothyronine (T3) & $95.7 \mathrm{umol} / \mathrm{ml}$ \\
Complete Blood Picture & \\
WBC & $14.5210^{9 / L}$ \\
Lymphocytes & $2.3610^{9 / \mathrm{L}}$ \\
Monocytes & $0.810^{9 / \mathrm{L}}$ \\
Neutrophiles & $11.2510^{9 / \mathrm{L}}$ \\
Eosinophiles & $0.0910^{9 / \mathrm{L}}$ \\
Basophiles & $0.00510^{9 / \mathrm{L}}$ \\
RBCC & $4.6710^{12 / L}$ \\
Hemoglobin & $14.1 \mathrm{~g} / \mathrm{dl}$ \\
Hematocrit ratio & $37.5 \%$ \\
MCV & $80.5 \mathrm{fL}$ \\
MCH & $30.1 \mathrm{pg}$ \\
MCHC & $37.6 \mathrm{~g} / \mathrm{dl}$ \\
RDW_CV & $16.2 \%$ \\
RDW_SD & $41.6 \mathrm{fL}$ \\
Erythrocyte Sedimentation Rate (ESR) & $65 \mathrm{~mm} / \mathrm{h}$ \\
C-Reactive Protein (CRP) & $35 \mathrm{mg} / \mathrm{dl}$ \\
\hline
\end{tabular}

\section{Discussion}

At this stage, the known cause for subacute granulomatous thyroiditis is viral infection of the upper respiratory airways. There are several viral infections which may contribute to the development of SAT, these include enterovirus, coxsackievirus, mumps, measles, and adenovirus. ${ }^{3}$ Having said that, there is little known about the role of COVID-19 in the pathogenesis of this disease and the development of its complications. ${ }^{4,5}$ Previous studies have shown SAT is more prevalent in females as compared to males. ${ }^{6}$

Considering the possibility of genetic predisposition and contagious characteristics observed in the same family members, human leukocyte antigen (HLA)-B35-mediated system is thought to play an active role in this mechanism.
The characteristic clinical finding of SAT is pain in the thyroid gland that is usually of a sudden onset. Pain may radiate to the neck or lower jaw area in severe cases and it may worsen with neck movements and coughing. ${ }^{1,2,5}$ Fever, weakness, and fatigue can also be observed due to both inflammation and mild hyperthyroidism, especially at the start of the disease. Palpitations, sweating, and tremors may occur due to high thyroid hormone titers in the blood. ${ }^{1,2}$ These findings usually disappear after 4-10 weeks following the improvement of the condition. The patient may develop asymptomatic, overt, or subclinical hypothyroidism following SAT. In this case study, the patient had normal thyroid function, but she complained of sore throat, fever, and difficulty in swallowing. She also had eating difficulty. Despite using a pain killer tablet, her symptoms remained. Her laboratory examination revealed leukocytosis, high CRP, and elevated ESR levels (Table 1). These are expected findings following SAT.

Her thyroid ultrasonography (Figure 1) showed large and multiple thyroid inflammation areas with patchy style. There was also slow blood flow to the gland. The thyroid gland was tender on placing the ultrasound probe and the patient complained of sever neck pain while performing the ultrasonography. Having said that, the ultrasonographic images were consistent with typical SAT diagnosis.

The pathophysiological process for the development of SAT following COVID-19 infection is similar to other known causative viruses, whether during the viral infection stage or following through the post-viral inflammation process. A study done in mid-2020, explained the correlation of the post COVID-19 infection and the development of SAT due to the viral affinity to angiotensin converting enzyme 2 (ACE2) receptors, which are more predominant in the thyroid cells when compared to the lung cells. ${ }^{8}$ As such, it is critical to consider SAT as a potential complication following COVID-19 infection. Most importantly, knowing that most of the new cases are asymptomatic. ${ }^{8}$ Careful examination of the neck looking for localized tenderness around the thyroid gland with laboratory investigation for thyroid function test is advisable for all patients following COVID-19 infection.

\section{Conclusion}

Physicians should consider SAT as a potential complication following COVID-19. Delayed diagnosis may result in severe pain and tenderness in the neck region which may reduce patient's quality of life following COVID-19 infection. Therefore, early thyroid function tests is recommended to be performed in patients with sore throat and fever.

\section{References}

1. Li, J.H., G.H. Daniels, and G. Barbesino, Painful Subacute Thyroiditis is Commonly Misdiagnosed as Suspicious Thyroid Nodular Disease. Mayo Clin Proc Innov Qual Outcomes, 2021. 5(2): p. 330-337.

2. Seyed Resuli, A. and M. Bezgal, Subacute Thyroiditis in COVID-19 Patients. Ear Nose Throat J, 2021: p. 1455613211012114.

3. Samuels, M.H., Subacute, silent, and postpartum thyroiditis. Med Clin North Am, 2012. 96(2): p. 223-33.

4. Brancatella, A., et al., Subacute Thyroiditis After Sars-COV-2 Infection. J Clin Endocrinol Metab, 2020. 105(7).
5. Mattar, S.A.M., et al., Subacute thyroiditis associated with COVID-19. BMJ Case Rep, 2020. 13(8)

6. Nishihara, E., et al., Clinical characteristics of 852 patients with subacute thyroiditis before treatment. Intern Med, 2008. 47(8): p. 725-9.

7. Desailloud, R. and D. Hober, Viruses and thyroiditis: an update. Virol J, 2009 6: p. 5

8. Muller, I., et al., SARS-CoV-2-related atypical thyroiditis. Lancet Diabetes Endocrinol, 2020. 8(9): p. 739-741. 